\title{
Detecção de tracoma e doenças corneanas em índios da região do Alto Rio Negiro
}

\author{
Trachoma and corneal diseases among indians of the Alto Rio Negro, Amazonas, Brazil
}

\author{
Ana do Carmo Paula Pessoa dos Reis ${ }^{1}$ \\ Cláudio Chaves ${ }^{1}$ \\ Jacob Moysés Cohen ${ }^{1}$ \\ Fernando Belfort ${ }^{2}$ \\ Norimar Pinto de Oliveira ${ }^{3}$ \\ Rubens Belfort Jr. ${ }^{2}$
}

\footnotetext{
${ }^{1}$ Instituto de Oftalmologia do Amazonas e Universidade Federal do Amazonas.

${ }^{2}$ Instituto da Visão, Departamento de Oftalmologia, Universidade Federal de São Paulo / Escola Paulista de Medicina (UNIFESP - EPM).

${ }^{3}$ Médico Residente do Departamento de Oftalmologia Universidade Federal de São Paulo / Escola Paulista de Medicina UNIFESP/EPM e integrante da Associação Saúde Sem Limites.

Endereço para correspondência: Cond. Cidade Jardim B1. 11/02 - Manaus (AM) CEP 69053-790.

E-mail: anadocarmo@bol.com.br

Recebido para publicação em 22.05.2001

Aceito para publicação em 15.11.2001
}

\section{INTRODUÇÃO}

A região do Alto Rio Negro situa-se no extremo noroeste do Estado do Amazonas, constituindo área de fronteira entre o Brasil, Colômbia e Venezuela e compreendendo território de $108.000 \mathrm{Km}^{2}$ de terras indígenas que se relacionam com os municípios brasileiros de São Gabriel da Cachoeira e Santa Isabel do Rio Negro. Esta região, considerada uma das mais pobres do Estado do Amazonas, entre outros fatores pequena quantidade de peixe em seus rios, é habitada por cerca de 30.000 índios (10\% do total estimado da população indígena no Brasil), que se distribuem por aproximadamente 500 aldeias ao longo de uma extensão de cerca de $3.000 \mathrm{~km}$ de rios, compreendendo 21 grupos étnicos das famílias lingüísticas Tukano, Arawak, Maku e Yanomami ${ }^{(1)}$.

Relatos recentes referem que nesta região existiria grande número de índios com tracoma ${ }^{(1-2)}$ e também presença expressiva de opacidades numulares na periferia corneana ${ }^{(3)}$, semelhantes às descritas em Pauiní no Estado do Amazonas atribuídas à Mansonella ${ }^{(4)}$ e entre os índios Yanomami de Roraima $^{(5-6)}$, causadas pela oncocercose.

No ano de 1997, uma equipe de profissionais da organização não governamental Associação Saúde Sem Limites registrou vários casos de tracoma, em estágios avançados, principalmente entre os índios Hupdë e Yohupdë (etnia Maku), habitantes das adjacências do Rio Tiquié(1). Ainda naquele ano foram assinalados, entre 486 pacientes examinados na sede do município de São Gabriel da Cachoeira, 3 casos de tracoma em indivíduos de etnia $\mathrm{Maku}^{(1)}$. Deste modo nota-se que, embora o tracoma provavelmente seja antigo na região, até o ano de 1997 a doença carecia de melhor caracterização epidemiológica que pudesse identificá-la como um sério problema de saúde pública no Alto Rio Negro.

Recentemente também a prevalência de glaucoma foi avaliada entre os índios desta região ${ }^{(7)}$, bem como a de pterígio ${ }^{(8)}$; em relação a esta doença foi descrito que $30 \%$ da população adulta examinada apresentava lesões com pelo menos $1 \mathrm{~mm}$ de crescimento sobre a córnea e 5,7\% apresentava pterígio com pelo menos $3 \mathrm{~mm}$ de crescimento sobre a córnea. 
Em continuidade ao trabalho de assistência e pesquisa de doenças oculares na região Amazônica realizou-se, através da parceria entre o Instituto da Visão (IPEPO) do Departamento de Oftalmologia da Universidade Federal de São Paulo / Escola Paulista de Medicina e o Instituto de Oftalmologia do Amazonas e Universidade Federal do Amazonas, o exame da população indígena da região do Rio Tiquié, afluente do alto Rio Negro.

\section{MÉTODOS}

Realizou-se estudo observacional simples no mês de julho de 1999, com o apoio do Governo do Estado do Amazonas, da Fundação Nacional do Índio, do Exército Brasileiro e da Associação Saúde Sem Limites, viagem à Pari Cachoeira, sede do $6^{\circ}$ Pelotão de Fronteira do Exército Brasileiro, localizada a cerca de $20 \mathrm{Km}$ da fronteira com a Colômbia, no Rio Tiquié.

Os pesquisadores aplicaram, junto a população local, questionário anotando nome, sexo, idade, família indígena, etnia, local da aldeia e realizaram o exame das pálpebras, cílios, conjuntiva, córnea e segmento anterior ocular com lupa de aumento e foco luminoso. Todos os pacientes tiveram também suas pálpebras evertidas para exame da conjuntiva tarsal superior. A avaliação quanto ao tracoma seguiu a classificação recomendada pela Organização Mundial de Saúde ${ }^{(3)}$, avaliandose em cada paciente o número de folículos e presença de cicatrização no tarso superior, bem como a presença de triquíase, entrópio e opacidades corneanas. Considerou-se como pterígio, crescimento mínimo de $2 \mathrm{~mm}$ de tecido sobre a córnea.

Foram consecutivamente examinados 179 índios (128 da etnia Tukano, 28 da etnia Maku e 23 de outras etnias) em 9 localidades ao longo do Rio Tiquié: 58 em Pari Cachoeira, 33 na comunidade de Bela Vista, 16 em Nova Fundação, 19 em Santo Antônio, 16 em São Sebastião, 14 em São João, 12 em Cucura, 6 em Maracajá e 5 pacientes em São José. O quadro 1 mostra a população de índios examinada, de acordo com a etnia, sexo e faixa etária.

\section{RESULTADOS}

Foram encontradas opacidades numulares corneanas em 51 dos 179 índios examinados (taxa de prevalência de 28,5\%) e 61 olhos, visto que em $20 \%$ dos pacientes as lesões eram bilaterais. O quadro 2 demonstra a freqüência das lesões numulares detectadas no exame da amostra populacional.

As opacidades numulares, de cor branca acinzentada, com

\begin{tabular}{|c|c|c|c|c|c|c|c|}
\hline \multicolumn{8}{|c|}{ Quadro 1. População examinada conforme etnia, sexo e faixa etária } \\
\hline \multirow[t]{2}{*}{ Idade } & \multicolumn{2}{|c|}{ Tukano } & \multicolumn{2}{|c|}{ Maku } & \multicolumn{2}{|c|}{ Outras etnias } & \multirow[t]{2}{*}{ Total } \\
\hline & Masc & Fem & Masc & Fem & Masc & Fem & \\
\hline$<15$ anos & 4 & 1 & 1 & 1 & 2 & 0 & 9 \\
\hline $15-30$ anos & 12 & 17 & 3 & 7 & 1 & 1 & 41 \\
\hline $31-60$ anos & 56 & 24 & 7 & 6 & 7 & 8 & 108 \\
\hline$>60$ anos & 8 & 6 & 1 & 2 & 2 & 2 & 21 \\
\hline Total & 80 & 48 & 12 & 16 & 12 & 11 & 179 \\
\hline
\end{tabular}

variações em número de uma a três lesões em um mesmo olho, tinham 1 a 2 mm de diâmetro, distavam do limbo cerca de 1 a 3 mm e localizavam-se preferencialmente em região das 2 às 5 e das 7 às 10 horas, sendo que nunca apresentavam neovascularização ou sinais de ulceração ou inflamação. Em nenhum dos casos a localização dessas lesões afetava a visão.

O pterígio foi encontrado em 23 índios, todos da etnia Tukano, com incidência pequena até os 30 anos (apenas um único caso). Frequientemente afetava os dois olhos e os lados nasal e temporal da córnea (Quadro 3).

Sinais de tracoma foram observados em 98 índios (55\% da população examinada). Os quadros 4 e 5 mostram a freqüência dos diagnósticos de tracoma (TF, TI, TS e TT/OC) e a presença de fossetas de Herbert na população examinada, de acordo com a etnia e faixa etária. Todos os 5 pacientes ( $2,8 \%$ da população) que apresentavam opacidades corneanas causadas pelo tracoma tinham visão inferior a conta dedos a 5 metros, sendo que, destes, 4 pacientes eram de etnia Maku. É importante salientar que foram evidenciadas diferentes formas de doenças nos olhos de um mesmo paciente, em muitos dos casos.

\section{DISCUSSÃO}

As opacidades numulares corneanas identificadas por este trabalho entre os índios do alto Rio Negro apresentaram

\begin{tabular}{|lcc|}
\hline Quadro 2. Distribuição das opacidades numulares corneanas \\
quanto ao olho afetado nas diferentes etnias
\end{tabular}

\begin{tabular}{|c|c|c|c|c|c|}
\hline \multicolumn{6}{|c|}{$\begin{array}{l}\text { Quadro 3. Freqüência de pterígio diagnosticado entre a } \\
\text { população tukano de acordo com a faixa etária }\end{array}$} \\
\hline \multirow{3}{*}{$\begin{array}{l}\text { Faixa etária } \\
<15 \text { anos }\end{array}$} & \multirow{3}{*}{$\begin{array}{c}\text { № de } \\
\text { índios } \\
0\end{array}$} & \multirow{2}{*}{\multicolumn{2}{|c|}{$\begin{array}{c}\text { Olho direito } \\
\text { Nasal Temporal }\end{array}$}} & \multirow{2}{*}{\multicolumn{2}{|c|}{$\frac{\text { Olho esquerdo }}{\text { Nasal Temporal }}$}} \\
\hline & & & & & \\
\hline & & 0 & 0 & 0 & 0 \\
\hline $15-30$ anos & 1 & 1 & 1 & 1 & 1 \\
\hline $31-60$ anos & 19 & 14 & 10 & 12 & 10 \\
\hline$>60$ anos & 3 & 3 & 1 & 1 & 1 \\
\hline Total & 23 & 18 & 12 & 14 & 12 \\
\hline
\end{tabular}

\begin{tabular}{|c|c|c|c|c|c|c|}
\hline \multicolumn{7}{|c|}{$\begin{array}{l}\text { Quadro 4. Freqüência dos achados relacionados ao tracoma d } \\
\text { acordo com a faixa etária }\end{array}$} \\
\hline Faixa etária & № pacientes & TF & TI & TS & TT/OC & FH \\
\hline$<15$ anos & 9 & 2 & 2 & 0 & 0 & 0 \\
\hline $15-30$ anos & 41 & 11 & 2 & 5 & 1 & 2 \\
\hline $31-60$ anos & 108 & 27 & 6 & 29 & 3 & 11 \\
\hline$>60$ anos & 21 & 4 & 3 & 8 & 1 & 3 \\
\hline TOTAL & 179 & 44 & 13 & 42 & 5 & 16 \\
\hline
\end{tabular}




\begin{tabular}{|c|c|c|c|c|c|c|}
\hline \multicolumn{7}{|c|}{$\begin{array}{l}\text { Quadro 5. Freqüência dos achados relacionados ao tracoma de } \\
\text { acordo com a faixa etária nas diferentes etnias }\end{array}$} \\
\hline Etnia Tukano & № pacientes & TF & TI & TS & TT/OC & FH \\
\hline$<15$ anos & 5 & 1 & 1 & 0 & 0 & 0 \\
\hline $15-30$ anos & 29 & 10 & 1 & 2 & 0 & 1 \\
\hline $31-60$ anos & 80 & 21 & 5 & 20 & 1 & 7 \\
\hline$>60$ anos & 14 & 3 & 1 & 5 & 0 & 2 \\
\hline Total & 128 & 35 & 8 & 27 & 1 & 10 \\
\hline Etnia Maku & № pacientes & TF & TI & TS & TT/OC & FH \\
\hline$<15$ anos & 2 & 1 & 1 & 0 & 0 & 0 \\
\hline $15-30$ anos & 10 & 1 & 1 & 3 & 1 & 1 \\
\hline $31-60$ anos & 13 & 3 & 0 & 6 & 2 & 4 \\
\hline$>60$ anos & 3 & 0 & 2 & 1 & 1 & 1 \\
\hline Total & 28 & 5 & 4 & 10 & 4 & 6 \\
\hline Outras etnias & № pacientes & TF & TI & TS & TT/OC & $\mathbf{F H}$ \\
\hline$<15$ anos & 2 & 0 & 0 & 0 & 0 & 0 \\
\hline $15-30$ anos & 2 & 0 & 0 & 0 & 0 & 0 \\
\hline $31-60$ anos & 15 & 3 & 1 & 3 & 0 & 0 \\
\hline$>60$ anos & 4 & 1 & 0 & 2 & 0 & 0 \\
\hline Total & 23 & 4 & 1 & 5 & 0 & 0 \\
\hline \multicolumn{7}{|c|}{$\begin{array}{l}\mathrm{TF}=\text { Tracoma Folicular } \mathrm{TI}=\text { Tracoma Inflamatório } \mathrm{TS}=\text { Tracoma cicatricial } \\
\mathrm{TT} / \mathrm{OC}=\text { Triquíase } / \text { Opacidade corneana } \mathrm{FH}=\text { Fosseta de Herbert }\end{array}$} \\
\hline
\end{tabular}

elevada freqüência (prevalência de 28,5\%). O pterígio foi encontrado em $12,8 \%$ da população examinada e somente entre os índios Tukano, provavelmente em virtude da maior proporção de indivíduos dessa etnia na composição da amostra populacional, e também pelo fato desses indígenas viverem e trabalharem frequientemente expostos ao sol, ao contrário dos outros silvícolas que trabalham no interior da floresta. Sinais de tracoma foram encontrados em $55 \%$ da população examinada e foram relativamente mais freqüentes entre a etnia Maku, sendo que entre esta etnia foi encontrada a maioria dos casos de deficiência visual secundária à doença.

A impressão clássica e histórica da inexistência de tracoma grave na Amazônia, pela alta disponibilidade de água que caracteriza a região é, pelo menos no alto Rio Negro, errônea, conforme demonstra este trabalho que confirma outros estudos recentes, todos apontando para a gravidade da situação gerada por esta doença. Medina e col., examinando índios do alto Rio Negro, encontraram freqüência de tracoma acima de $30 \%$ entre crianças e $70 \%$ entre os mais idosos. É muito provável que a doença esteja há muitas gerações entre estes índios e a menor proximidade e contato com a água seja o grande fator de risco na população de nível econômico mais precário e que habita áreas mais distantes dos rios, explicando deste modo o fato da maior freqüência e severidade do tracoma verificadas neste trabalho entre os Maku, índios nômades que, distintamente dos outros grupos indígenas da região, costumam habitar áreas afastadas dos leitos dos grandes rios, localizadas no interior da floresta.

Este artigo confirma a existência de grande frequiência e gravidade de pterígio entre os índios do alto Rio Negro, similar ao que ocorre em outras regiões da Amazônia $^{(8)}$, como por exemplo, a grande quantidade de radiação solar a que são expostos os habitantes da região equatorial. As causas para esta alta incidência são desconhecidas e podem estar relacionadas a fatores ambientais. A existência de opacidades numulares de córnea, não relacionadas ao tracoma, podem estar associadas a etiologias desconhecidas ou a quadros de filariose como mansonelose, descrita na população do município de Pauiní, Amazonas ${ }^{(4)}$, ou a oncorcencose detectada entre os índios yanomami de na fronteira do Brasil com a Venezuela no estado de Roraima ${ }^{(6)}$.

\section{ABSTRACT}

Purpose: To assess the ophthalmic conditions of Brazilian Indians from the Alto Rio Negro at the border of Brazil and Colombia. Methods: Ophthalmologic examination of 179 indians in July 1999. Results: Nummular corneal opacities in $28.5 \%$; pterygium in $12.8 \%$; trachoma in $55 \%$. Of the total examined indians $2.8 \%$ had vision below counting fingers at 5 meters because of corneal lesions secondary to trachoma.

Keywords: Pterygium/diagnosis; Trachoma/diagnosis; Mansonella/purification and isolation; South-American indians

\section{AGRADECIMENTOS}

Técnico Rene Coimbra, FUNAI; Tenente Sílvio Fernandes Marques, Exército Brasileiro, Prof. Dr. Roberto Baruzzi-Universidade Federal de São Paulo e, Dr. Amazonino Mendes, Governador do Estado do Amazonas.

\section{REFERÊNCIAS}

1. Programa de controle do tracoma entre a população indígena do Alto Rio Negro. Saúde Sem Limites. 1998. [mimeografado].

2. Alves APX, Oliveira NP, Medina NH, Machado M, Athias R, Cruz AAV. Hidden trachoma in the brazilian rain forest. Invest Ophthalmol Vis Sci 40(Suppl)4:29, 1999 .

3. Garrido CMB. Saúde ocular em comunidades de índios e não índios na região do alto Rio Negro, Estado do Amazonas [tese]. Universidade Federal de São Paulo; 1999. 97p.

4. Branco BC, Chamon W, Belfort N, Belfort Jr R, Costa AJA. Achados oculares entre os habitantes do município de Pauiní e possível associação entre lesões corneanas e mansonelose na Amazônia. Arq Bras Oftalmol 1998; 61:674-82.

5. Belfort Jr. R, Moraes M. Oncocercose ocular no Brasil. Rev Assoc Méd Bras 1979;25:123-8.

6. Chaves C. Ocular onchocerciasis in Brazil. Bull Trop Med Int Health 1997;5:6.

7. Carvalho RC, Rodrigues MLV, Garrido C, Thorn F, Cruz AAV. Prevalence of glaucoma among the indigeneous people of the upper amazon basin. [abstract] Invest Ophthalmol Vis Sci 1998; (suppl.39):S1044.

8. Garrido C, Carvalho RC, Thorn F, Cruz AAV. Pterygia \& cataracts in forest dwelling and riverside indigeneous people of the upper amazon basin. [abstract] Invest Ophthalmol Vis Sci 1998;(suppl. 39):S1044. 